\title{
NAVIGATING MATTERS OF CONCERN IN PARTICIPATORY DESIGN
}

\author{
Brodersen, Søsser; Pedersen, Signe \\ Aalborg University
}

\begin{abstract}
Among $75-90 \%$ of residents in Danish nursing homes are diagnosed with dementia. This article explore how a team of five 3rd semester bachelor's design students sought to improve quality of life for elderly people with dementia in a nursing home through a co-design process of a new sensory stimulation technology. Participatory Design researchers agree that it is important to involve diverse actors in the design process such as elderly with dementia, nursing home management, nursing staff etc. But when involving many different actors in designing new products, services and systems the challenge is to navigate the many perspectives and concerns of these actors, which is often conflicting and hence needs negotiating.'We draw upon the ANT framework to analyse how 'matters of concern' (MoCs) are negotiated and to discuss how designers navigate by staging and facilitating design interactions to support negotiation of MoCs among numerous actors during the design process.
\end{abstract}

Keywords: Participatory design, Design engineering, Collaborative design

\section{Contact:}

Brodersen, Søsser

Aalborg University

Department of Planning

Denmark

sbro@plan.aau.dk

Cite this article: Brodersen, S., Pedersen, S. (2019) 'Navigating Matters of Concern in Participatory Design', in Proceedings of the 22nd International Conference on Engineering Design (ICED19), Delft, The Netherlands, 5-8 August 2019. DOI:10.1017/dsi.2019.102 


\section{INTRODUCTION}

Since the early 70'ies engineers and other designers have studied users and involved them in testing new solutions. However, the participatory design tradition takes this to a new level as they not only study the users, but rather actually invites them to actively participate in the design activities (Sanders \& Stappers, 2008). The cornerstone of participatory design is, that people who are going to use a product or solution should also be involved in designing it (Namioka, Schuler, \& Blomberg, 1993). As Bratteteig \& Gregory argue “...participatory design approaches seek to include future users in most parts of the design process, even as co-designers. Ideally, users at many levels participate so that change can be shaped from several perspectives." (Bratteteig \& Gregory, 2001, p. 63). But involving multiple actors in the design process also allow for controversies to arise which means that the designer often needs to navigate between conflicting aspirations and concerns. This has led participatory designers such as Iversen, Halskov, \& Leong (2012) to promote the importance of negotiating (sometimes conflicting) values, as these cannot be identified by a priori assumptions, but rather are subject to negations and emerge in collaboration with diverse stakeholders (Bratteteig \& Gregory, 2001). In this article we build on their work and illustrate how a design team of 5 engineering design students stages, facilitates and synthesises negotiations of matters of concern (MoCs). The students are for the first time attempting to make use of participatory design approaches and activities such as prototypes and design games to involve nursing staff, elderly residents with dementia and the management at a Danish nursing home, where this study takes place, actively in the design process.

\subsection{Negotiating concerns using prototypes and other objects}

Recent contributions within participatory design draw upon Actor Network Theory (ANT) as a theoretical framework to address and discuss networks-in-the-making. The word actor refers to people as well as to non-humans such as mock-ups and prototypes. Being a constructivist approach the general idea is that networks are constructed through negotiations of actors' concerns (Binder, Brandt, Ehn, \& Halse, 2015; Latour, 2008; Linde, 2012; Storni, Binder, Linde, \& Stuedahl, 2015). As opposed to matters of fact, matters of concern are characterised by being rich, complex, surprising and constructed. These characteristics make concerns political and open for discussion, negotiation, conflict and compromise (Björgvinsson, 2008; Latour, 2005; Storni et al., 2015). We argue, that in participatory design such negotiations are often carefully staged and navigated by a designer (Pedersen \& Clausen, 2017) and draw attention towards the designers ability to navigate the design process by staging, facilitating, and learning from/synthesising the results of negotiations (Pedersen, 2016).

As the ontological claim of ANT is, that humans and non-humans are equally important and hence should be studied symmetrically (Shiga, 2007), this means that materiality, as well as humans are invited into these 'spaces' to partake in the negotiations. Prototypes and other objects such as design games (Brandt, Messeter, \& Binder, 2008) can be seen as key actors in many participatory design projects as they (if staged and navigated properly) have the ability to mediate negotiations by providing a shared or new reference point between e.g. designers and other actors, to translate actors (intentionally or not - and towards a common ground or apart) and to represent ideas, actors' concerns, i.e. as the result of negotiations. If so, they can be termed intermediary objects (Blanco, Boujut 2003; Vinck 2012). "...following the intermediary objects produced and mobilised during interactions between actors helps to describe how these objects facilitate, foster or complicate the building of compromises and the sharing of knowledge" (Winck 2013, pp. 97).

Since the materiality used for negotiation might represent the concerns of the involved actors, we will in the case presented hereafter follow the development and refinement of materiality such as prototypes from one 'space' for interaction to the next in order to identify and analyse negotiations, controversies and translation processes.

\section{THE CASE: EASE TENTIONS BETWEEN ELDERLY PEOPLE WITH DEMENTIA AND NURSING STAFF}

In this case we explore how a team of five engineering design students as part of their 12 weeks 3rd semester at the bachelor-engineering programme Sustainable Design at Aalborg University sought to improve quality of life for elderly people with severely evolved dementia in a nursing home in 
Denmark. During the course of the semester, the students were introduced to user involvement, participatory design methods, and prototyping techniques and thus they had no prior knowledge about these subjects before the semester started. Over the period of 12 weeks, the team carried out field studies and staged multiple user involvement activities using design games and prototypes as intermediary objects with both the elderly people and the staff at the nursing home. Our analysis is based on the students written work (Olsen, Didriksen, Olsgaard, Nilsen, \& Larsen, 2016), observations while they carried out their research and qualitative interviews with staff from the nursing home. Involvement of vulnerable actors such as people with cognitive impairments like dementia is often a challenging task. Hendricks et al puts it: "codesign methods frequently draw upon exactly those skills that people living with cognitive or sensory impairments have problems with" (Hendriks, Slegers, \& Duysburgh, 2015). Here referring to the ability to speak or apply abstract or creative thinking. And although the students did not always succeed, they tried to their best ability to involve the nursing home residents in the project.

\subsection{Framing of the problem}

It is estimated that among 75-90\% of residents in Danish nursing homes are diagnosed with dementia. Dementia causes severe challenges to the people diagnosed with it, as the condition makes them unable to express certain needs, wishes, and inconveniences. Often this disability to express themselves is reflected in restlessness, frustrations and anger (Association, 2017). One means to ease the restlessness and frustrations among elderly people with dementia is to use sensory stimulation technologies, such as the Paro seal, music, light sensors etc. (see for example http://snoezelhuset.gentofte.dk/da/Om-Snoezelhuset). These sensory stimulations technologies were the starting point for a collaboration between the student design team and the nursing home. The main concern articulated by the management of the nursing home at the initial meeting, was the increasing number of residents with dementia due to the demographics mixed with the continued savings in the Danish healthcare sector. This combination will eventually result in reduced quality of living for the residents, as the staff will have less time to care for their needs. To help the elderly suffering from restlessness and ease the work of the nursing staff, sensory stimulation technologies are perceived as an important mean by the nursing management. However, they felt that they needed more knowledge on how to use the technologies and when - which was why they approached the engineering design students.

Thus, during the first meeting between the nursing home and the student group, a common concern was to analyse sensory stimulation technologies and how they can provide ease to the elderly people with dementia.

\subsection{No activities in the sensory stimulation technology room}

Initially the design team started doing observations in the specific room appointed to these technologies at the nursing home. However, it soon became apparent to them, that only very few activities were carried out in the room, leaving the technologies non-used. The design team assumed that a reason could be found in the challenges of getting the residents out of their apartments and into the room. Knowing the concerns of the nursing home management, the design team decided to engage first the residents and second their nursing staff to understand their lives, their concerns and which types of activities that would make them happy and comfortable.

\subsection{Engaging elderly people with dementia}

The design team was challenged in relation to how to engage the residents, since the effects of the disease makes it difficult to relate to a conversation or objects not familiar with them (Hendriks, Huybrechts, Wilkinson, \& Slegers, 2014; Hendriks et al., 2015; Lindsay et al., 2012; Robinson, Brittain, Lindsay, Jackson, \& Olivier, 2009; Rodgers, 2016). With these challenges in mind, the design team decided just to experiment with different objects to see if any of them could assist in involving the residents in a dialogue about their preferred activities. The game (Figure 1: Illustration of the first design game consisted of game pieces with photos of activities that were familiar to the residents. The 'ladder' in the left picture, was meant to frame and prioritise their interests. 

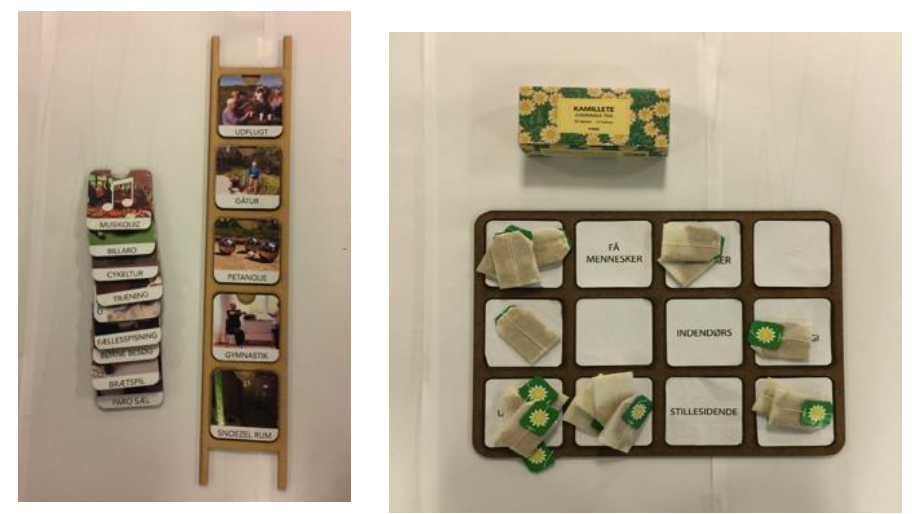

Figure 1: Illustration of the first design game

The dialogue was staged in the activity centre of the nursing home, and after having tried to engage 4 residents in a dialogue, the design team realised the materiality assumed a higher abstraction level, than the residents was able to engage in. The residents simply did not know what to do and just stared at the design team, while others wandered away. Thus, the design game did not succeed in acting as an intermediary object between the residents and the team. However, an important learning from these interactions was, that the team needed to come up with another approach to engage this particular group of actors. Since it was important for the team to engage with the residents to understand their concerns and motivations, they decided to stage a new dialogue based on a different design game. With basis in the same pieces as in the first dialogue, the team engaged the residents in a dialogue about the pictures and asked them to assign a smiling or angry smiley to each activity in accordance to whether they liked it or not (see Figure 2).


Figure 2: Illustration of the second and modified design game

Again, it was difficult to keep the residents focused in the dialogue, and the pictures and smileys again appeared to be too abstract for the residents to relate to. Furthermore, the dialogues once again took place in the 'activity centre' where most residents walk in and out, watch television, or do various activities. The team designed yet another design game providing structure and an element of choice (see Figure 3). Furthermore, the dialogue was staged in another setting, e.g. the resident's own apartments, providing comfort and tranquillity.

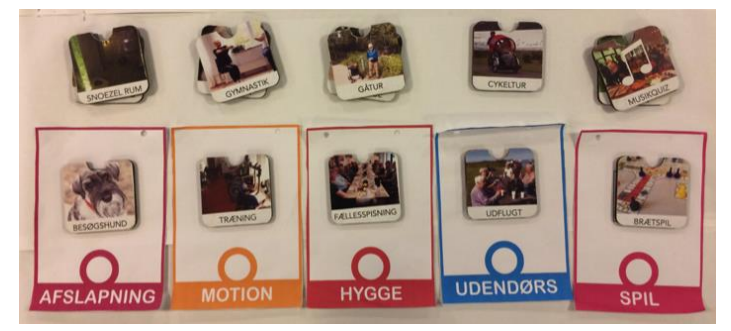

Figure 3: Illustration of the third and yet again modified design game (Note: 'Afslapning' = Relaxation, 'Motion' = Fitness, 'Hygge' = Cosiness, 'Udendørs' = Outdoor and 'Spil' = Gaming)

The staging and facilitation of this third dialogue, around a new and improved object (design game) eventually succeeded in engaging the elderly people in a dialogue and through the intermediary object 
allowing the elderly people to express what made their life meaningful and what would make them feel at ease. These wishes and concerns were related to social activities, i.e. excursions, playing games, walking; being independent, i.e. able to dress and bath themselves and being understood, i.e. to communicate.

Having identified key concerns for the elderly people with dementia, the design team started synthesising the knowledge gained in a physical affinity diagram made up of posits. This affinity diagram represented yet another object important to the design process as it represented the concerns of the residents, the nursing home management as well as desk research about dementia and sensory technologies. The synthesis showed that sensory stimulating technologies were a concern for the nursing home management, but none of the residents associated these technologies with activities they had found worth mentioning. Furthermore, the affinity diagram provided structure, overview and helped the students remember their desk research related to the challenges of living with dementia. The desk research revealed, that the unease and restlessness of elderly with dementia often results in tensions and conflicts between the residents and the nursing staff where the residents might yell at or even hit the staff while trying to assist them. Thus, the design team translated their design focus to being concerned with improving the interaction between the nursing staff and the elderly people to avoid potential conflict and thus provide ease in the residents' daily lives.

All this information was synthesised and translated by the team into a design specification. However, before the design team would be ready to start conceptualising ideas and concepts, they found it important to dig deeper into the relation between the residents and the nursing staff. Through engaging the residents, the team had become aware of their concerns of social activities, being independent and being understood - and together with the findings from their desk research the students at this point also wanted to involve the nursing home staff in their activities.

\subsection{Understanding the interaction between residents and nursing staff}

During one week, the team made observations of the staff's practices and engaged in informal interviews by following them in their daily routines. They particularly focused on situations where they sensed the residents became agitated and frustrated, as these would also be the situations where sensory stimulation technology might assist. By following the nursing staff and the residents, it became apparent for the design team, that especially three situations occurred during the day in which the residents felt frustrated. The observed situations where: 1) during the morning routines of getting up and dressed, 2) when the residents had to leave the nursing home for e.g. a doctor's visit, and 3) just after the breakfast, when the residents were to attend activities in the activity centre. In these specific situations, the team had observed, some of the residents being so angry and frustrated, that they attempted to hit the nursing staff or throw objects.

The design team's argument was, that if the residents are uncomfortable and frustrated, it might be due to them not been understood. And in such situations, their anger and frustration mean, that they will not be willing to participate in any activity suggested to them - let alone activities involving technology.

Thus, the team staged a dialogue with some of the nursing staff to learn about the three identified situations. They translated their newly gained knowledge and experience into a sequence analysis design game (inspired by the 'sequence model'(Cross, 2005)) which they hoped would allow the staff to talk freely about conflicts and concerns related to the three situations. The three situations were individually separated into sub-tasks. Each of these sub-tasks were written on game pieces, for example 'change of diaper', 'lifting from bed to wheelchair', 'making up the bed', 'brushing teeth', 'washing face' etc. Smaller pieces were made, indicating when challenges appeared (visualized as 'bumps on the road'). The intention with the dialogue was for the staff to relate to their routines and indicate, when they felt challenges arose (see Figure 4).

The nursing staff recognised the teams' observations about when conflicts arose and explained that in these particular situations, the residents are very little in control as they are $100 \%$ dependent of the staff. 

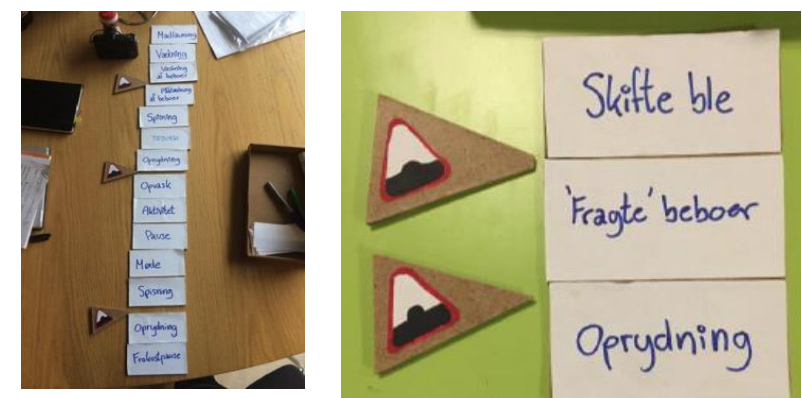

Figure 4: The sequence analysis design game. The game pieces to the left illustrating road bumps and the writing to the right saying: Change diaper, moving resident and cleaning.

During the dialogue it became apparent that the staff often felt conflicts arise in one-to-one situations making it difficult for them to carry out meaningful care. The staff raised the idea of a future sensory technology being mobile, enabling the residents to use such technologies inside their own apartments where conflicts mainly arise. The team immediately followed up on this idea by opening up for dialogue about functions and use of a potential future solution.

\subsection{Knowledge translated into a design specification}

These new insights were translated by the team into a second version of the design specification, adding elements of functionality, use, mobility and non-verbal interaction as themes that where central for designing a good solution. In this way the design specification became an important intermediary object between the members of the team, since it represented the concerns of residents, staff and management which were translated into requirements to the future solution. It also represented an important internal decision taken in this process - that instead of encouraging the residents to use the sensory stimulation room, a mobile sensor-stimulating device was now to be developed.

\subsection{Prototype intervention through cultural probes}

Based on the updated design specification, the team began an ideation phase to explore new solutions for mobile sensor stimulation in one-to-one situations. The students wanted to test which kind of stimulation that would ease the residents the most in conflicting situations. They found inspiration in literature on cognitive stimulation and they translated stimulation into sound, light and tactility, and developed three low fidelity prototypes (see Figure 5).


Figure 5: Low fidelity prototypes (Left: light effect; Middle: sound. Right: tactility)

The team staged a prototype intervention with the nursing staff and the residents to facilitate relatively rapid cycles of making, telling and enacting (Sanders \& Stappers, 2014). To ensure ownership among the nursing staff, each prototype was assigned to a 'prototype ambassador' amongst the staff, whose job was to test the prototype and engage the residents as well as follow staff members in the testing. The team further designed a cultural probe to encourage the nursing staff to reflect on the potential usefulness of the prototypes during their daily care practices. The staff were to reflect on during which time during the day, the effect, the mobility and the success of the prototypes.

After the interventions a follow-up interview was carried out with the staff focusing on whether the prototypes had a calming effect on the residents during one-to-one situation. In general, the staff was very pleased with the prototypes as the they had a positive effect on the residents. Based on the tests the staff came up with further demands to the solution: Easy to use in a bed, at chair or even at the bathroom; easy to clean; and have rounded edges for safety reasons. These insights were synthesised and translated into the design specification, making it more detailed and precise. 


\subsection{The nursing staff as co-designers of sub-solutions}

The design was still quite rough in this point of time, so the team staged a new intervention with two nursing staff and two musical therapists, aiming at co-designing a range of solutions that would meet the new requirements. One of the central configuring elements was a morphology model, with six themes from the design specification: mobility, functions, situations, shape, instructions and flexibility - all represented by pictograms.

During the co-design session a lot of interesting ideas were generated. However, during the morphology session the team realised that most of the solutions suggested by the staff was based on already existing solutions. This made the team reflect that perhaps they had staged and framed the negotiations and the solution too narrowly. To make up of these dubious design choices, the team chose to stage a new brainstorming session. However, as the nursing staff could not allocate time for this within a few days of reaction, the team decided to do a brainstorming session among themselves and add these ideas to the ideas generated by the staff in an overall morphology chart (see Figure 6).

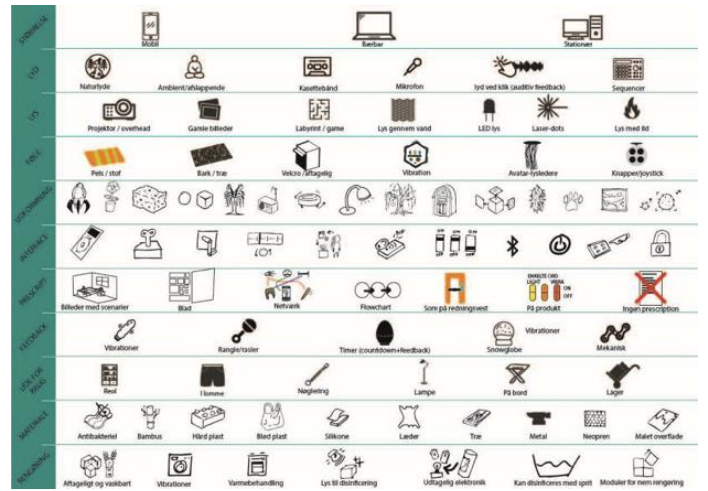

Figure 6: Morphology scheme with sub-solutions from staff and the design team

\subsection{Conceptualisation and deciding on the final concept}

Based on the overall morphology chart, the team drew up three concepts to discuss with the staff. In the ideation process the team ensured that the ideas for sub-solutions generated by the nursing staff was included in the three concepts to make sure that the nursing staff felt represented and thus could recognise their ideas and feel ownership of the concepts. The three concepts developed by the design team were:

1. Concept Willow is a lamp that can be placed in the elderly persons' room as an integrated part of the interior. Touching the lamp will stimulate light and sound.

2. Concept Radio is shaped like an old fashion radio that, when touched, it will play sounds like birds singing, the ocean, the wind etc.

3. Concept Feel-It is shaped like a stone, which the residents can feel in their hands. By touching the lightweight 'stone', it can vibrate and light up in different colours that will distract and ease the person. The size makes it easy to carry around as it can fit in a pocket.

The team made visual presentations in the form of drawings of the three concepts, which acted as intermediary objects in a following concept dialogue with the staff. During this dialogue, the staff argued, that the 'willow' appeared too much as an ornament and they feared the elderly people would move it around or throw it away in conflicting situations. The 'radio' could create confusion since it looked like a radio, but didn't work as a radio. The 'feel-It' was easy to bring along, the staff liked the idea of it both providing vibration and light as well as it being mobile and thus could be used in different settings. However, it would be important that it was light-weight, in case the residents in anger would throw it.

With the feedback in mind, the team conducted a more formal evaluation of the concepts in their design studio where the concepts were evaluated based on their ability to meet the criteria's identified in the design specification. Part of the evaluation also included a feasibility study. Eventually everything pointed to the selection of the 'Feel-It' as the concept, which showed the most potential.

\subsection{Final intervention}

Over the following two weeks, the team developed a high-fidelity prototype of the Feel-It concept (see Figure 7), which represented the various actors' concerns structured in the design specification as well 
as the negotiated overall concern of the project. It required programming of lights and sound as well as selection of materials which can be seen as a negotiation with the technology in terms of what was possible to prototype. With a functioning prototype ready, the design team staged one final intervention at the nursing home. The intervention was carried out over a period of two weeks, in which the earlier appointed prototype ambassadors again was given the responsibility of testing the prototype to see whether it had a positive influence on the residents.

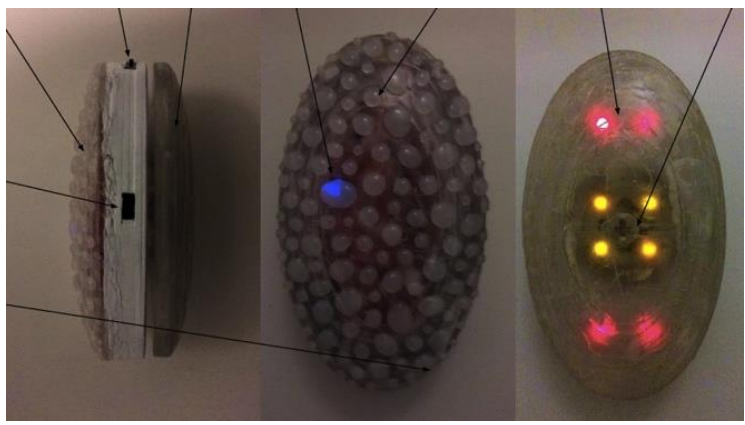

Figure 7: The final prototype used in the final intervention

After the intervention, the team staged and facilitated a smaller workshop, in which the staff provided feedback. During this workshop the staff highlighted that Feel-It was easily embedded in their existing care practices and was easy to carry around and bring from one room to another. In their opinion, it provided stimulation to the residents by giving them ease in stressed situations: “... so then Peter, Hans and Karen are calm, when they have it (the Feel-It) in their hands and touches it".

However, the caregivers also suggested a number of improvements, for instance that the object was not familiar to the residents, which in some cases had created a bit of confusion. Also, the prototype was too big to carry around in a pocket, the sound and vibration length needed to be extended, the surface needed to be developed in another material making it lighter and easier to clean, as well as cheap to manufacture.

This being a student project means that their initial engagement ends here. However, the team have considered to continue to work with this later in their studies and incorporate the recommendations from the staff. This would also involve more engagements with the residents as they will probably also have useful ideas for improvement.

\section{DISCUSSION}

We set out to analyse the navigational moves of a design team and to illustrate how they (try to) orchestrate the design process by staging and facilitating negotiations of multiple actors' concerns during a design process. During the course of the project a number of interventions was staged and facilitated around non-human actors such as design games, prototypes, probes but also affinity diagrams, design specifications, morphologies etc. The object used in one intervention is often redesigned and used as a central element in the next. This was for instance seen in the first prototyping intervention, where the nursing staff highlighted the importance of making the device easy to clean, without sharp corners, easy to use, and usable for the residents while in bed, setting in a chair or in the bathroom. This information was translated into the design specification as requirements. Thus, we have illustrated how knowledge travels through the forms of diverse intermediary objects that mediate the dialogue and represent the concerns of the involved actors.

There are numerous negotiations taking place during the project. Firstly, the overall concern of the project was negotiated between the nursing home management and the student team to centre around providing ease and comfort through sensory stimulating technologies. Following, the team managed to involve the residents as well as the nursing staff by using materiality to visualise and represent both their individual concerns as well as the overall project concern. After a couple of attempts, the team managed to identify three major concerns of the residents. With these concerns as the starting point, the staff were invited to participate in the process through observations, morphology-sessions, prototype-ambassadorship, cultural probes and feedback sessions. And through the involvement the overall framing and concern of the project was negotiated and reframed from being concerned with the fixed sensory stimulation technology room to instead revolve around mobile sensory stimulating technologies to be used in one-to-one situations. 


\subsection{Reflections of the involvement efforts}

During the semester, the students was continuously encouraged to use inspiration from the Scandinavian participatory design tradition. Obviously, the students could have engaged more with the residents rather than relying on the staff during the testing phase. However, working with people with dementia is challenging, even for people with years of experiences within the field of participatory design and user involvement. And the students were indeed challenged. Not only were they to learn how to navigate between diverse concerns and motivations from multiple actors (residents, staff, and nursing home management), they also have to navigate and involve cognitively impaired elderly people with dementia who in their daily lives relies on their loved ones and on the nursing home staff, when they are to communicate and express themselves.

Focus in this particular project and thus also in this paper have been on sensory technologies as this was the initial frame and concern of the nursing home management. However, we would like to emphasise that technologies might not turn out to be the most appropriate way to address the challenges elderly people with dementia experiences. Needless to say that such technologies should never stand alone, but needs to be part of a holistic social-pedagogic approach of the nursing staff (which is why it was crucially important for the students to engage the staff and give them ownership of the process).

\section{CONCLUDING REMARKS}

By following how a team of 3rh semester engineering design students staged a series of negotiations by actively using different objects such as design games, sequence analysis, design specifications and prototypes, we see how the students tried to navigate between multiple actors' concerns. This particular project was indeed challenging, as the students not only involved staff and nursing home management but at the same time struggled to involve the cognitively impaired residents which have difficulties expressing themselves on a daily basis. The students designed and produced a multiplicity of objects with different purpose and fidelity which in most cases worked as intermediary objects as they represented the actors' concerns and well as the result of the negotiations. Also, especially the prototypes managed to mediate between team and staff as well as between staff and residents. Furthermore, as a result of the negotiations that took place during the process, the overall concern of the project was reframed from focusing on the use of the sensory stimulation technology room to rather focus on mobile technologies that would provide comfort and a sense of ease during the daily care activities performed by the nursing staff.

\section{REFERENCES}

Association, T. D. A. (2017), The Danish Alzheimer Association. Retrieved from http://www.alzheimer.dk/kommunalvalg/temaer/uddannelseaf-personale\%0D

Binder, T., Brandt, E., Ehn, P. and Halse, J. (2015), "Democratic design experiments: between parliament and laboratory". CoDesign, Vol. 11 No 3-4, 152-165. http://doi.org/10.1080/15710882.2015.1081248

Björgvinsson, E. B. (2008), "Open-ended participatory design as prototypical practice". CoDesign, Vol. 4 No. 2 , pp. 85-99. http://doi.org/10.1080/15710880802095400

Blanco, EricBoujut, J. F. (2003), "Intermediary Objects as a mean to foster Co-operation". Engineering Design Computer Supported Cooperative Work, Vol 12 No. n 2, pp. 205-219.

Brandt, E., Messeter, J. and Binder, T. (2008), "Formatting design dialogues - games and participation". CoDesign, Vol. 4 No. 1, pp. 51-64.

Bratteteig, T. and Gregory, J. (2001), "Understanding Design". Proceedings of the 24th Information Systems Research Seminar in Scandinavia (IRIS 24), p. 3.

Cross, N. (2005), Engineering Design Methods: Strategies for Product Design (3rd ed.). Milton Keynes, UK: WILEY.

Hendriks, N., Huybrechts, L., Wilkinson, A. and Slegers, K. (2014), "Challenges in doing participatory design with people with dementia". In Proceedings of the 13th Participatory Design Conference on Short Papers, Industry Cases, Workshop Descriptions, Doctoral Consortium papers, and Keynote abstracts - PDC '14 volume 2 (pp. 33-36). http://doi.org/10.1145/2662155.2662196

Hendriks, N., Slegers, K. and Duysburgh, P. (2015), "Codesign with people living with cognitive or sensory impairments: a case for method stories and uniqueness". CoDesign, Vol. 11 No. 1, pp. 70-82. http://doi.org/10.1080/15710882.2015.1020316

Iversen, O. S., Halskov, K. and Leong, T. W. (2012), "Values-led participatory design". CoDesign, Vol. 8 No. 2-3, pp. 87-103. http://doi.org/10.1145/2399016.2399087 
Latour, B. (2005), "From Realpolitik to Dingpolitik or How to Make Things Public". In P. Latour, B. and Weibel (Ed.), Making Things Public: Atmospheres of Democracy (pp. 14-41). Cambridge: MIT Press, ZKM, Center for Art and Media.

Latour, B. (2008), “A Cautious Prometheus? A Few Steps Toward a Philosophy of Design (with Special Attention to Peter Sloterdijk)". In "Networks of Design” (pp. 2-10). University College Falmouth, Cornwall, United Kingdom: Universal Publishers. Retrieved from http://books.google.com/books?hl=en\&amp;lr=\&amp;id=3B5bbv0r-

EkC\&amp;oi=fnd\&amp;pg=PA2\&amp; $\mathrm{dq}=\mathrm{A}+\mathrm{Cautious}+$ Prometheus?+A+Few+Steps+Toward+a+Philoso phy+of+Design+(with+Special+Attention+to+Peter+Sloterdijk\&amp;ots=BENSsMyS03\&amp;sig=6iebJo 1hrW2idy0DTtcUUscMi2

Linde, P. (2012), "Design and the "Manyness" of Things". In P. Linde, T. Binder, C. Storni, \& D. Stuedahl (Eds.), Exploring ANT in PD: reflections and implications for theory and practice (pp. 9-10). Roskilde, Denmark: PDC.

Lindsay, S., Brittain, K., Jackson, D., Ladha, C., Ladha, K. and Olivier, P. (2012), "Empathy, participatory design and people with dementia". In Proceedings of the 2012 ACM annual conference on Human Factors in Computing Systems - CHI '12 (p. 521). Austin, Texas. http://doi.org/10.1145/2207676.2207749

Namioka, A., Schuler, D. and Blomberg, J. (1993), Participatory Design: Principles and Practices. (D. Schuler and A. Namioka, Eds.). Taylor \& Francis.

Olsen, A., Didriksen, A., Olsgaard, C., Nilsen, E. and Larsen, T. (2016), Design og Anvendelses af Prototyper. Student report. Sustainable Design BD3. Copenhagen.

Pedersen, S. (2016), Navigating prototyping spaces. Aalborg University, Copenhagen.

Pedersen, S. and Clausen, C. (2017), "Staging Collaborative Innovation Processes". In The XXVIII ISPIM Innovation Conference - Composing the Innovation Symphony. Vienna, Austria.

Robinson, L., Brittain, K., Lindsay, S., Jackson, D. and Olivier, P. (2009), “Keeping in Touch Everyday (KITE) project: Developing assistive technologies with people with dementia and their carers to promote independence". International Psychogeriatrics, Vol. 21 No. 3, pp. 494-502. http://doi.org/10.1017/S1041610209008448

Rodgers, P. (2016), Designing with People Living with Dementia.

Sanders, E. B.-N. and Stappers, P. J. (2008), "Co-creation and the new landscapes of design". CoDesign, Vol. 4 No. 1, pp. 5-18. http://doi.org/10.1080/15710880701875068

Sanders, E. B.-N. and Stappers, P. J. (2014), "Probes, toolkits and prototypes: three approaches to making in codesigning". CoDesign, Vol. 10 No. 1, pp. 5-14. http://doi.org/10.1080/15710882.2014.888183

Shiga, J. (2007), "Translations: Artifacts from an Actor-Network Perspective". Artifact, Vol. 1 No. 1, pp. 40-55. http://doi.org/10.1080/17493460600658318

Storni, C., Binder, T., Linde, P. and Stuedahl, D. (2015), "Designing things together: intersections of co-design and actor-network theory". CoDesign, Vol. 11 No. 3-4, 149-151. http://doi.org/10.1080/15710882.2015.1081442

Vinck, D. (2012), “Accessing Material Culture by Following Intermediary Objects”. In L. Naidoo (Ed.), An Ethnography of Global Landscapes and Corridors (pp. 89-108). INTECH Open Access Publisher. Retrieved from http://www.intechopen.com/books/an-ethnography-of-global-landscapes-and-corridors 